\title{
Effects of foliage invertebrate availability and forest structure on the abundance of the critically endangered Rota White-eye Zosterops rotensis in Rota, Mariana Islands
}

\author{
LAINIE ZARONES, MELANIE R. COLÓN, JAMES C. HA and RENEE R. HA
}

\section{Summary}

The Rota White-eye, Zosterops rotensis, is a critically endangered species endemic to the island of Rota, in the Mariana Islands, western Micronesia. There has been a dramatic decline in both its population size and range over the past few decades. The population, estimated at approximately 1,000 individuals in 1999, is found exclusively in 300 ha of mature limestone forest, though nearby areas of mature limestone forest remain unoccupied. We compared the bird community, vegetation characteristics and foliage-invertebrate density in forest plot pairs with known high and low densities of Rota White-eyes. Discriminant function analysis suggested that certain vegetation characteristics were best at predicting whether a plot was high-density or low-density. High-density plots had more stems with $20-50 \mathrm{~cm} \mathrm{DBH}$, more foliage intercepts at 3-9 m, more epiphytes, greater total canopy cover and fewer overall plant species. This information is essential for the protection of the current habitat of the Rota White-eye and for future efforts in the protection and management of this species.

\section{Introduction}

The Rota White-eye Zosterops rotensis is a "Critically Endangered" species on the IUCN Red List (BirdLife International 2010) and a US federally endangered species (USFWS 2004). It is endemic to the island of Rota in the Commonwealth of the Northern Mariana Islands, western Micronesia. The species has shown drastic declines in both range and population size in recent decades. In 1944, it was described as 'numerous' (Baker 1948) and surveys in 1982 yielded a population estimate of around 10,700 individuals (Engbring et al. 1986). However, surveys conducted from 1996 to 1999 indicated that the population had since fallen to approximately 1,00o individuals (Amidon 2000, Fancy and Snetsinger 2001). There have been no white-eye population surveys since then; however observations show that the distribution of the white-eye has not decreased, and may have in fact expanded (L. Zarones pers. obs.). The Rota White-eye is currently restricted to less than 300 ha of mature limestone forest above elevations of $150 \mathrm{~m}$ (Amidon 2000, 2004, Fancy and Snetsinger 2001). Nearby mature limestone forest areas exist that are not presently occupied by the Rota White-eye, though the reasons these areas are currently unoccupied are unknown (Amidon 2000, 2004, Fancy and Snetsinger 2001). It has been suggested that harassment and/or predation by the introduced Black Drongo Dicrurus macrocercus may be in part responsible for the decline in the white-eye population (Craig and Taisacan 1994), but this has yet to be confirmed (Fancy and Snetsinger 2001, USFWS 2007).

The Rota White-eye is insectivorous and feeds primarily on invertebrate specimens gleaned from leaves and branches of the tree canopy (Craig and Taisacan 1994, Amidon 2000, Johnson 2007). 
Wet mature forest may have a more complex foliage structure and increased amount of mid-level foliage and therefore may offer more foraging substrates and prey availability to the white-eye (Amidon 2000). However, we currently lack information on which habitat characteristics, such as food availability, forest structure and forest composition, determine the suitability of some forested areas for white-eyes compared to others (Amidon 2000, Fancy and Snetsinger 2001, USFWS 2007). Proper management of this endangered and declining species requires its habitat requirements to be identified. To that end, we examined the relationship between forest structure and composition and food availability in wet limestone forest with high and low densities of white-eyes on Rota.

\section{Methods}

\section{Study area}

Rota is the second most southerly of the Mariana Islands, in western Micronesia $\left(14^{\circ} \mathrm{Og}\right)^{\prime} \mathrm{N}$, $145^{\circ} 12^{\prime} \mathrm{E}$ ). The island is of volcanic origin with a total area of $86 \mathrm{~km}^{2}$ and a maximum elevation of $491 \mathrm{~m}$. The island is primarily characterised by limestone but also contains exposed areas of volcanic origin. The climate is tropical marine with an annual rainfall of approximately $200 \mathrm{~cm}$. The vegetation is composed of primary and secondary limestone forest, agroforestry, strand, and grassland (Falunruw et al. 1989, USFWS 2007). In 1979, nearly 60\% of the island remained forested (Falunruw et al. 1989), but much of this forest is heavily degraded (Engbring et al. 1986).

We established 14 high-density white-eye plots and 14 low-density white-eye plots in wet, mature limestone forest on the slopes below the Sabana region in areas known as Lupok, Palii, Fanlagon, As Mundo, Mananana, Uyulan Hulo and As Akoddo. The As Akoddo, Uyulan Hulo and Mananana regions (north-facing) were characterised by Merrilliodendron megacarpum-dominated forest, while As Mundo, Palii, Fanlagon and Lupok (north-east, south-west and south-facing, respectively) featured forest dominated by Elaeocarpus joga and Hernandia labyrinthica (or H. sonora at lower elevations). We located plots $\left(100 \mathrm{~m}^{2}\right)$ using white-eye distribution maps (Fancy and Snetsinger 2001), previously established plots that had been surveyed for white-eyes (Amidon 2000) and on-the-ground observations. We paired high and low-density plots and matched them for region, forest type, elevation and aspect. All plots were at least $150 \mathrm{~m}$ apart from each other.

\section{Foliage invertebrate sampling}

We conducted foliage invertebrate sampling in August 2006 by collecting a single branch from two trees of each of five tree species in each plot: Elaeocarpus joga, Hernandia labyrinthica (or the similar H. sonora in one pair of plots below $250 \mathrm{~m}$ elevation), Macaranga thompsonii, Merrilliodendron megacarpum and Premna obtusifolia. These species are the five most commonly used trees for foraging by the Rota White-eye (Amidon 2000), though not all species were present in all plot pairs. We selected individual trees haphazardly within each plot by dividing the plot into four quadrats, randomly selecting two of the quadrats, then selecting the first tree of that species we found in each quadrat. If there were no trees of that species in one or both of the quadrats we searched the other two quadrats in a similar manner until we had found two trees, or else determined that the species was not present in the plot.

Amidon (2000) observed that foraging by Rota White-eyes occurred most frequently on perches less than $1 \mathrm{~cm}$ in diameter and at least $3 \mathrm{~m}$ high. Using the branch clipping technique described by Schowalter et al. (1981) and Johnson (2000), we collected branch samples that were 3-9 $\mathrm{m}$ high and had less than $1 \mathrm{~cm}$ stem diameter. We raised a telescopic pole with a hoop and garbage bag attached to the end so that the branch was in the garbage bag. We then pulled a drawstring to close the bag, and cut the branch using branch pruners on top of a second telescopic pole and lowered the bag to the ground. We sprayed the branch samples in each bag with insecticide and then sealed the bag and transported them to the laboratory. 
We thoroughly searched each branch for invertebrates, which we removed using forceps and placed in a vial containing $70 \%$ isopropyl alcohol. We separated the leaves and sticks of each branch and air-dried them. Finally, we dried all vegetative material in a drying oven for 24 hours at $50^{\circ} \mathrm{C}$ and weighed the dried material to determine the dry leaf weight of each sample.

We identified insects as far as possible to order or family. As not all tree species were present in each plot, we only included samples from tree species that were present in both the high and low-density plot of each pair. We used the dry leaf weights of branch samples to calculate the number of invertebrates of each taxon per $100 \mathrm{~g}$ of dry leaf. There has been no detailed dietary study of the Rota White-eye to date, so we do not yet know exactly which types of invertebrates they consume. However, by sampling total invertebrates in the canopy (foraging substrate) we obtained an indication of potential food availability per $100 \mathrm{~g}$ of dry leaf matter in high and low-density white-eye areas.

\section{Bird surveys}

Amidon (2000) showed that the maximum distance Rota White-eyes could be reliably surveyed with $100 \%$ detectability was $25 \mathrm{~m}$. We performed forest bird surveys in each plot in July 2006 and repeated surveys in September 2006. We conducted a 25 -m radius point count at each corner of each plot for $10 \mathrm{~min}$, between dawn and 1oh3o, taking care not to record individuals more than once. The average of these four corner counts was calculated for each plot. We recorded wind speed on a scale of o (smoke rises vertically), I (wind direction shown by smoke drift) or 2 (wind felt on face, leaves rustle). We did not conduct surveys when the wind was stronger than 2 or if there was any rain. We calculated the average number of birds from the four point counts conducted in each plot, but kept the July and September replicates separate.

\section{Vegetation surveys}

We surveyed vegetation characteristics in April-May 2007 in four 10 x 10 m quadrats placed in each of the four quarters of the plot. We recorded average canopy height using a $15-\mathrm{m}$ pole marked at $1-m$ intervals. We used a densiometer to record the total canopy cover facing the four cardinal points in the centre of each quadrat. We recorded foliage density by counting the number of $10-\mathrm{cm}$ intervals on a $15-\mathrm{m}$ pole that were intercepted by foliage at $\mathrm{o}-3 \mathrm{~m}, 3-9 \mathrm{~m}$ and $9-15 \mathrm{~m}$. We counted the number of stems with a diameter at breast height (DBH) of $5-20 \mathrm{~cm}, 20-50 \mathrm{~cm}$ and $>50 \mathrm{~cm}$ and the percentage of stems in each quadrat that had branches with epiphytes (ferns, orchids or mosses).

\section{Analysis}

We conducted a three-stage analysis of results: 1 ) an initial comparison of bird surveys, vegetation and foliage invertebrate counts between the high and low-density plot pairs, 2) a Principal Components Analysis (PCA) to reduce the variables to independent factors, and 3) a Discriminant Function Analysis (DFA) to identify which variables most accurately identified plots as high-density or low-density. We used SYSTAT for all analyses.

We performed a paired t-test to initially compare vegetation characteristics of plot pairs and repeated-measure ANOVAs to compare the July and September bird counts in low and high-density plots. Species that were counted in fewer than half the surveys were excluded from analysis.

We used the Shapiro-Wilks test to check for normality of invertebrate counts and vegetation characteristics and transformed variables using log-n, log-10 or square root transformations where necessary to achieve normal distributions. As some of the 11 invertebrate and 10 vegetation variables were likely to be correlated, we performed PCA to generate two sets of uncorrelated variables. We then used the four invertebrate factors and three vegetation factors in a DFA to test which factors best predicted whether a plot was a low-density or high-density plot. We included all 
Table 1 . Mean \pm standard error of forest birds counted in 14 high and 14 low-density Rota White-eye plots, July and September 2006.

\begin{tabular}{|c|c|c|c|c|c|c|c|c|c|}
\hline & \multicolumn{2}{|c|}{ Low-density mean $\pm \mathrm{SE}$} & \multicolumn{2}{|c|}{ High-density mean $\pm \mathrm{SE}$} & \multirow{2}{*}{$\frac{\text { Low }}{\text { Jul and Sep }}$} & \multirow{2}{*}{$\frac{\text { High }}{\text { Jul and Sep }}$} & \multicolumn{3}{|l|}{$F$} \\
\hline & Jul & Sep & Jul & Sep & & & Low/high & Jul/Sep & Interaction \\
\hline Micronesian Honeyeater & $0.59 \pm 0.12$ & $0.55 \pm 0.12$ & $0.71 \pm 0.14$ & $0.63 \pm 0.10$ & $0.57 \pm 0.12$ & $0.67 \pm 0.12$ & 0.66 & 0.26 & 0.048 \\
\hline Rufous Fantail & $0.66 \pm 0.17$ & $0.79 \pm 0.11$ & $1.43 \pm 0.22$ & $1.34 \pm 0.18$ & $0.72 \pm 0.14$ & $1.38 \pm 0.20$ & $9 \cdot 72^{* * *}$ & 0.019 & 0.69 \\
\hline Rota White-eye & $0.96 \pm 0.38$ & $0.43 \pm 0.16$ & $4.20 \pm 0.67$ & $4.30 \pm 0.81$ & $0.70 \pm 0.30$ & $4.25 \pm 0.73$ & $25 \cdot 46^{* * *}$ & 0.33 & 0.74 \\
\hline Micronesian Starling & $3.29 \pm 0.42$ & $3.68 \pm 0.39$ & $3.18 \pm 0.36$ & $2.95 \pm 0.28$ & $3.48 \pm 0.40$ & $3.06 \pm 0.32$ & 0.83 & 0.12 & 1.82 \\
\hline
\end{tabular}

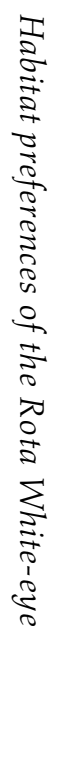


Table 2. Mean \pm standard error of vegetation characteristics for 14 high and 14 low-density Rota White-eye plots.

\begin{tabular}{lccc}
\hline & High Mean \pm SE & Low mean \pm SE & $t$ \\
\hline Canopy height $(\mathrm{m})$ & $8.14 \pm 0.51$ & $7.00 \pm 0.40$ & 1.918 \\
Total canopy cover & $85.13 \pm 2.12$ & $76.96 \pm 1.25$ & $10.99^{* *}$ \\
Foliage intercepts $0-3 \mathrm{~m}$ & $2.42 \pm 0.24$ & $2.40 \pm 0.18$ & 0.004 \\
Foliage intercepts 3-9 m & $6.74 \pm 0.65$ & $3.80 \pm 0.36$ & $15.6^{* * *}$ \\
Foliage intercepts 9-15 m & $1.10 \pm 0.33$ & $0.47 \pm 0.16$ & 3.032 \\
Number of species & $3.61 \pm 0.35$ & $4.68 \pm 0.33$ & $5.017^{*}$ \\
Stems 5-20 cm & $16.00 \pm 1.63$ & $16.98 \pm 1.38$ & 0.219 \\
Stems 20-50 cm & $3.48 \pm 0.40$ & $2.07 \pm 0.44$ & $5.661^{*}$ \\
Stems 50 cm+ & $0.59 \pm 0.18$ & $23.74 \pm 4.73$ & 0.000 \\
$\%$ trees with epiphytes & $27.16 \pm 5.44$ & & 0.225 \\
\hline
\end{tabular}

${ }^{*} P<0.05,{ }^{* * P}<0.01,{ }^{* *} P<0.001$.

factors initially, then performed a backwards stepwise removal of factors to identify which were the fewest set of predictive factors that maximised the predictive power of whether a plot was highdensity or low-density.

\section{Results}

We counted 1o forest bird species in our forest bird surveys (Philippine Turtle-dove Streptopelia bitorquata, White-throated Ground Dove Gallicolumba xanthonura, Mariana Fruit-dove Ptilinopus roseicapilla, Collared Kingfisher Todiramphus chloris, Micronesian Honeyeater Myzomela rubratra, Black Drongo Dicrurus macrocercus, Rufous Fantail Rhipidura rufifrons, Mariana Crow Corvus kubaryi, Rota White-eye, and Micronesian Starling Aplonis opaca). Six of these species (Philippine Turtle-dove, White-throated Ground Dove, Mariana Fruit-dove, Collared Kingfisher, Black Drongo, Mariana Crow) were detected too infrequently in surveys (less than half) for further analysis.

There was a significant difference in the number of Rota White-eyes and Rufous Fantails between the high and low-density plots in both July and September (Table 1). Rota White-eyes were the most commonly recorded species within the high-density plots, and were significantly more common in high-density plots than in low-density plots, as expected (Table I). The second most common species in high-density plots, and the most common species in low-density plots, was the Micronesian Starling. No species were more common in low-density plots.

Total canopy cover, foliage intercepts at 3-9 $\mathrm{m}$ and stems of $20-50 \mathrm{~cm}$ DBH were significantly higher in high-density plots, while the total number of plant species was significantly lower in high-density plots (Table 2 ).

High-density plots had significantly fewer Coleoptera, but there were no other differences in the number of individuals of 11 invertebrate groups between high and low-density plots (Table 3 ).

Four PCA factors were generated from the counts of the 11 most common invertebrate groups, and three PCA factors were generated from the 1o vegetation characteristics (Table 4). The PCA showed correlations among vegetation characteristics. Canopy cover, stems with $20-50 \mathrm{~cm} \mathrm{DBH}$ and the percentage of trees with epiphytes were positively correlated, while the total number of species was negatively correlated with the above, showing that dark, wet forests with numerous mid-sized stems had lower overall diversity. Stems $>50 \mathrm{~cm}$ and canopy height were positively correlated with one another, and negatively with stems of $5-20 \mathrm{~cm}$ and foliage intercepts at o-3 $\mathrm{m}$, indicating large tall trees had fewer small stems and less foliage density near to the ground.

Backwards stepwise DFA identified two variables (VEGI and VEG 3 ) that were most able to correctly classify plots as low or high-density in $86 \%$ of cases (Jackknifed classification, Wilks' 
Table 3. Mean \pm standard error of invertebrate taxa (number of individuals per $100 \mathrm{~g}$ of dry leaf material) collected in up to five tree species in 14 high and 14 low-density Rota White-eye plots.

\begin{tabular}{lccc}
\hline Taxon & High-density mean \pm SE & Low-density mean \pm SE & $t$ \\
\hline Acari & $38.5 \pm 12.1$ & $54.1 \pm 26.7$ & 0.282 \\
Formicidae & $172.8 \pm 63.7$ & $139.3 \pm 17.3$ & 0.259 \\
Araneae & $32.6 \pm 5.8$ & $35.0 \pm 4.6$ & 0.104 \\
Coccoidea & $75.5 \pm 33.4$ & $76.8 \pm 30.5$ & 0.001 \\
Coleoptera & $12.96 \pm 1.6$ & $26.5 \pm 4.1$ & $9.617^{* *}$ \\
Collembola & $20.1 \pm 5.2$ & $11.8 \pm 4.9$ & 1.373 \\
Diptera & $98.7 \pm 80.0$ & $30.4 \pm 13.8$ & 0.710 \\
Membracoidea & $58.1 \pm 19.2$ & $58.7 \pm 13.7$ & 0.001 \\
Lepidoptera & $18.6 \pm 2.5$ & $16.9 \pm 3.0$ & 0.188 \\
Psocoptera & $17.7 \pm 5.0$ & $16.7 \pm 7.6$ & 0.011 \\
Gastropoda & $115.4 \pm 34.5$ & $103.1 \pm 27.4$ & 0.077 \\
\hline
\end{tabular}

$* * P<0.01$

Lambda $=0.5414, \mathrm{df}=2,1,26$, approximate $\mathrm{F}=10.59, \mathrm{df}=2,25, P=0.0005)$. Thus, the following vegetation variables characterised high-density white-eye plots: increased percentage of stems with epiphytes, more stems with $20-50 \mathrm{~cm}$ DBH, greater canopy cover, more foliage intercepts at 3-9 $\mathrm{m}$, and fewer total plant species. These vegetation characteristics indicate a darker, wetter forest, with dense mid-storey and a simpler composition. Neither foliage invertebrates nor bird species were shown to contribute to classification of low and high-density white-eye plots.

\section{Discussion}

Historical records indicate that the species was once more widely distributed on Rota and was found down to sea level (Baker 1948, USFWS 2007). However, the structure of much of the forested areas on Rota appears to have changed from denser, wetter forests to more open, drier ones due to agricultural activities, browsing by the introduced Philippine deer, Rusa marianna, and recent increases in typhoon effects (Amidon 2000, Fancy and Snetsinger 2001, USFWS 2007). Typhoon activity has both increased in intensity and proximity to Rota since 1952, which may have negatively affected forest bird populations on the island (Ha et al. 2012). Changes in forest structure may have reduced the amount of suitable habitat and hence the distribution and population size of the Rota White-eye (Amidon 2000). This is supported by the results of the

Table 4. PCA factors and correlation direction in invertebrate counts (INV $1-4$ ) and vegetation characteristics (VEG 1-3).

\begin{tabular}{|c|c|c|}
\hline PCA factor & Positive & Negative \\
\hline $\mathrm{INV}_{1}$ & $\begin{array}{l}\text { Diptera, Psocoptera, Lepidoptera, Araneae, } \\
\text { Gastropoda }\end{array}$ & \\
\hline $\mathrm{INV}_{2}$ & Acari, Formicidae & \\
\hline $\mathrm{INV}_{3}$ & & Collembola \\
\hline $\mathrm{INV}_{4}$ & & Coleoptera, Coccoidea, Membracoidea \\
\hline VEGI & $\begin{array}{l}\% \text { trees with epiphytes, stems } 20-50 \mathrm{~cm} \text {, } \\
\text { canopy cover }\end{array}$ & Total species \\
\hline $\mathrm{VEG}_{2}$ & Stems $50 \mathrm{~cm}+$, canopy height & Stems $5-20 \mathrm{~cm}$, foliage intercepts $\mathrm{o}-3 \mathrm{~m}$ \\
\hline $\mathrm{VEG}_{3}$ & Foliage intercepts $3-9 \mathrm{~m}$ & \\
\hline
\end{tabular}

(Foliage intercepts $9-15 \mathrm{~m}$ did not fall clearly into any one factor). 
current study, which found that the Rota White-eye is far more abundant in wetter forests with more dense foliage and stem density. This type of forest may provide more substrates for foliagegleaning insectivores.

The Rota White-eye is currently restricted to 300 ha of steep slopes featuring wet, dense forest. Such areas are difficult to access and develop and are therefore protected from anthropogenic habitat alteration. However, a typhoon or other natural disaster could potentially destroy the remaining habitat and thus the remaining population. Similarly, increased browsing by the introduced Philippine deer may further limit the availability of suitable habitat. Finally, the spread of the brown tree-snake Boiga irregularis from the adjacent island of Guam to Rota would almost certainly result in extinction of the Rota White-eye, given its extremely small distribution and population (USFWS 2007). The introduction of the brown tree-snake on Guam resulted in the extinction of the related Guam Bridled White-eye Zosterops conspicillatus, as well as nearly all other native forest birds on Guam, including the Mariana Crow (Savidge 1987, Ha et al. 2010). For the long-term conservation of the species, it is necessary that not only the remaining inhabited areas be protected, but that forest alteration and destruction be reversed so that Rota White-eye distribution can increase to its former extent. In addition, the information on habitat preferences can be used in captive breeding and relocation programs if deemed necessary for the protection of the species.

Our analysis did not reveal that the abundance of any one foliage invertebrate group was positively or negatively associated with the high-density white-eye plots. However the greater foliage substrate in the high-density plots may provide more prey items per unit area, even if the abundance of invertebrate groups per $100 \mathrm{~g}$ of dry leaf material is no different. There is not much information on the identity of prey items consumed by Rota White-eyes, although they have been observed feeding a variety of prey items to their nestlings, including Lepidoptera adults (moths) and larvae, and possibly Gastropoda, Araneae, Tettigoniidae, Coleoptera and Ephemoptera (S. Faegre in litt.).

This study shows that forests with certain characteristics contain higher abundances of Rota White-eyes, but did not elucidate the cause. There could be a range of reasons, including food availability, nesting preferences, predator avoidance, or a combination of these. The limitation of this study is that the comparison is descriptive only and habitat quality is inferred from abundance. Such descriptive comparisons assume we know enough about the species to be able to measure habitat quality directly (Johnson 2007). Animals are assumed to choose higher-quality habitat (though with exceptions-see Kristan 2007). However, patterns of avian habitat selection are complex, and understanding the influence of habitat selection on population regulation is challenging (Zimmerman et al. 2009). Experimental studies on the effects of why certain habitat characteristics affect Rota White-eye populations that provide more information than descriptive inferences are needed (Johnson 2007); however such an approach can be problematic when dealing with endangered species.

We recorded very few Black Drongos in both the high-density and low-density plots. The Black Drongo is more commonly found in more open habitats. While it is possible that Black Drongos are excluding Rota White-eyes from open habitat, this does not explain why the white-eye is less common in some closed forests. Nevertheless, denser forests may provide more shelter from larger birds, or the smaller white-eye may only remain competitive in such areas. A long-term comparison of the change in distribution and abundance of the Rota White-eye with changes in habitat structure could shed light on this.

In conclusion, forest plots with higher densities of Rota White-eye had more stems of $20-50 \mathrm{~cm}$ $\mathrm{DBH}$, more foliage intercepts at 3-9 $\mathrm{m}$, more epiphytes, greater total cover and fewer overall species, compared with forest plots with lower densities of white-eyes. The counts of individuals per invertebrate groups were not shown to differ between high-density plots and low-density plots; however, the higher stem densities and foliage dense forest in the high-density plots may provide more feeding substrates for white-eyes. Alternatively, the more dense forest may provide more refuge from predators, or it might be more competitive for food and other resources in such habitat. Such knowledge on habitat requirements of the Rota White-eye is essential for optimal habitat 
protection, habitat enhancement and creation, and potentially captive breeding, reintroduction and relocation programs and ultimately for the preservation of the species.

\section{Acknowledgements}

Funding for this work was provided by the Commonwealth of the Northern Mariana Islands Division of Fish and Wildlife, and the U.S. Fish and Wildlife Service Section 6 endangered species grants. Laura Williams and Shelly Kremer provided logistical and funding support for our work in the CNMI. Fred Amidon assisted in locating study plots and vegetation sampling techniques, Haldre Rogers provided advice on invertebrate sampling techniques, James Stanford, Mayumi Knight and Jaron Stanaway assisted in the field, Kathy Lofdahl and Lynn Raulerson provided access to drying ovens at the University of Guam, and Lauren Pulliam and Emily Weiser assisted in identification of invertebrate samples. Sarah Faegre provided information on Rota White-eye prey items from observations made by videotaped nests, as well as helpful comments on the manuscript.

\section{References}

Amidon, F. A. (2000) Habitat relationships and life history of the Rota bridled whiteeye (Zosterops rotensis). Thesis. Blacksburg, Virginia: Virginia Polytechnic Institute and State University.

Amidon, F. A. (2004) Breeding biology of the endangered Rota Bridled White-eye. Wilson Bull. 116: 342-346.

Baker, R. H. (1948) Report on collections of birds made by United States Naval Medical Research Unit No. 2 in the Pacific war areas. Smithsonian Miscellaneous Collection 107: 1-74.

BirdLife International (2010) Zosterops rotensis. In: IUCN 2011. IUCN Red List of Threatened Species. Version 2011.2. <www. iucnredlist.org $>$

Craig, R. J. and Taisacan, E. (1994) Notes on the ecology and population decline of the Rota Bridled White-eye. Wilson Bull. 106: 165-169.

Engbring, J., Ramsey, F. L. and Wildman, V. J. (1986) Micronesian forest bird survey, 1982: Saipan, Tinian, Agiguan, and Rota. U. Honolulu, HI: US Fish and Wildlife Service.

Falanruw, M. C., Cole, T. G. and Ambacker, A. H. (1989) Vegetation survey of Rota, Tinian, and Saipan, Commonwealth of the Northern Mariana Islands. U.S. Forest Service, Resource Bulletin PSW-27.

Fancy, S. G. and Snetsinger, T. J. (2001) What caused the population decline of the Bridled White-eye on Rota, Mariana Islands?
Pp. 274-28oin J. M. Scott, S. Conant and C. Van Riper III, eds. Evolution, ecology, conservation, and management of Hawaiian birds: a vanishing avifauna. Lawrence, Kansas: Cooper Ornithological Society. Allen Press. (Studies in Avian Biology No. 22).

Johnson, M. D. (2000) Evaluation of an arthropod sampling technique for measuring food availability for forest insectivorous birds. J. Field Ornithol. 71: 88-109.

Johnson, M. D. (2007) Measuring habitat quality: a review. Condor 109: 489-504.

Ha, J. C, Buckley, J., and Ha., R. R. (2012). The potential for typhoon impact on bird populations on the island of Rota, Northern Mariana Islands. Micronesica 43: 214-224.

Kristan, W. B. (2007) Expected effects on correlated habitat variables on habitat quality and bird distribution. Condor 109: 505-515.

Savidge, J. A. (1987). Extinction of an island forest avifauna by an introduced snake. Ecology 68: 660-668.

Schowalter, T. D., Webb, J. W, and Crossley, D. A. Jr. (1981) Community structure and nutrient content of canopy arthropods in clearcut and uncut forest ecosystems. Ecology 62: 1010-1019.

USFWS (2004) Endangered and threatened wildlife and plants; endangered status for the Rota bridled white-eye (Zosterops rotensis) from the Commonwealth of the Northern Mariana Islands; final rule. Federal Register 69: 3022-3029. 
USFWS (2007) Draft recovery plan for the Nosa Luta or Rota Bridled White-eye (Zosterops rotensis). Portland, Oregon: US Fish and Wildlife Service.
Zimmerman, G. S., Gutiérrez, R. J., Thogmartin, W. E. and Banerjee, S. (2009) Multiscale habitat selection by Ruffed Grouse at low population densities. Condor 111: 294-304.

\section{LAINIE ZARONES*}

Department of Psychology, University of Washington, Seattle, WA 98195, U.S.A.

Present address: Oklahoma Biological Survey, University of Oklahoma, Norman, OK 73019, U.S.A.

\section{MELANIE R. COLÓN}

Department of Psychology, University of Washington, Seattle, WA 98195, U.S.A.

Present address: Department of Wildife and Fisheries Sciences, Texas A\&M University, College Station, TX 77840 , U.S.A.

JAMES C. HA, RENEE R. HA

Department of Psychology, University of Washington, Seattle, WA 98195, U.S.A.

*Author for correspondence; email: lainiezarones@gmail.com

Received 3 February 2012; revision accepted 18 July 2012; Published online 1o April 2013 